\title{
Por meio do meio: crítica para uma teoria dos meios (de comunicação)
}

\author{
Maurício Liesen \\ http://orcid.org/0000-0002-8518-4886 \\ I - UFPR \\ Curitiba (PR). Brasil
}

Resumo: Este trabalho estrutura-se como um estudo histórico-conceitual do conceito de meio, contrastando-o com termos similares, tais como mídia, medium e médium. Após um breve estudo etimológico, analisa-se as especificidades da relacionalidade inerente a este conceito, ilustrada pela locução por meio de ou através de, em contraste a termos como prótese, signo e canal, tratados frequentemente pela literatura da área como sinônimos de meio. O intuito aqui não é apenas fundamentar a pertinência de uma teoria (ou campo de estudos) específica dos meios, mas ainda delinear suas particularidades face a abordagens comunicacionais, instrumentais e semióticas.

Palavras-chave: estudos dos meios; filosofia dos meios; epistemologia da comunicação; medium.

Abstract: Through the "means". Critique for a (communication) media theory - The text at hand is structured as a historical-conceptual study of "means" as a concept, contrasting it with similar terms, such as media and medium. After a brief etymological study, we analyze the specificities of the inherent relationality of that concept, illustrated by the preposition "through" or "by means of", in contrast to terms like prosthesis, sign and channel, often treated by Communication Studies as synonyms for "means". Our goal here is not only to argue the pertinence of a media theory (or studies), but also to outline their particularities in the face of communicational, instrumental and semiotic approaches.

Keywords:media studies; media philosophy; epistemology of communication; medium. 


\section{O meio revisitado}

O que é um meio? As inúmeras respostas a essa pergunta variam, obviamente, de acordo com o contexto ou quadro epistemológico no qual ela se insere. O meio pode ter um sentido topológico ou geométrico (p.ex. um meio entre dois pontos, um espaçoentre); um sentido cronológico (p.ex. o meio-dia, um intervalo, o presente situado entre o passado e o futuro); um sentido quantitativo ou lógico (p.ex. o meio-termo, a média); um sentido qualitativo (p.ex. o mediano, o misturado). Essa categorização, mesmo que bastante incompleta', já dá uma noção do gigantesco espectro semântico dessa pequena palavra.

Mas, se pudéssemos delimitar um meio-termo do termo meio, se pudéssemos apontar um ponto de contato ou contínuo entre as mais diferentes acepções dessa palavra, poderíamos afirmar que meio é sempre um conceito relacional. Seja simbólica ou concreta, qualquer relação só pode ocorrer se seus elementos estão ao mesmo tempo afastados e postos em contato por outra coisa que não eles mesmos. Dito de outra maneira: o que está em relação, o que se dá, o que aparece, o que se transmite, o que se anuncia só pode ocorrer através ou por meio de outra coisa que não ele mesmo. A relacionalidade pode ser entendida, portanto, como a função medial - a medialidade - que, diferentemente da função representacional da partícula como, com-forma a aparição daquilo que é mediado. Logo, o estudo de um meio significaria, antes de tudo, ocupar-se de um através de, de um por entre, de um no decurso de, de um por meio de.

O objetivo deste breve ensaio é problematizar esse denominador comum do conceito de meio (expresso na locução por meio de) e algumas de suas implicações epistemológicas a partir do sentido "mediológico" (SCHMITZ-EMANS, 2006, p. 9), ou seja, a partir da definição do meio como medium (e de seu respectivo plural, media). Usar essa palavra latina em detrimento de termos como mídia e meios de comunicação pode causar certo estranhamento, mas, como esperamos deixar claro através deste texto, esse termo tem uma vantagem em relação aos outros por designar um problema que poderíamos chamar propriamente de "medial", e não de uma questão técnica ou semiótica.

Inicialmente, dois sentidos desse termo latino chamam a nossa atenção na tentativa de figurar esse problema medial ${ }^{2}$. De um lado, em seu sentido gramatical, medium designa uma voz existente no grego antigo, a voz média, situada entre as vozes passiva e ativa ${ }^{3}$, ou seja, nela o sujeito do verbo é ao mesmo tempo agente e paciente da ação. Como não há voz verbal correspondente na língua portuguesa, o medium pode ser associado à voz reflexiva (p. ex. "vestir-se") ou a construções como, por exemplo, "esta embalagem

1 Para uma abordagem mais sistemática dos significados teóricos e filosóficos do termo "meio", cf. RÖTTGERS; SCHMITZ-EMANS, 2006; RÖTTGES, 1980; SCHRÖTER, 2014.

2 Sempre é bom lembrar que o jogo etimológico aqui apresentado deve ser tomado como inspiração ou figuração de um problema teórico, mas nunca como um argumento, já que o uso de determinados termos que possuem uma complexa tradição dentro do pensamento ocidental demandaria, naturalmente, provas e explicações mais elaboradas.

3 Para um estudo detalhado com os variados usos da voz medium do grego antigo, cf. ALLAN, 2003. 
se recicla" (no sentido de "ela é reciclável"), mas seu campo semântico é bem mais complexo. Para a nossa discussão, devemos somente reter o seu aspecto intermediário entre a atividade e a passividade, já que uma característica de todo meio é de ao mesmo tempo afetar e ser afetado por uma outra coisa que não ele próprio.

Por outro lado, medium também é uma tradução da palavra grega $\mu \varepsilon \tau \alpha \xi u ́$ (metaxú), que designa o advérbio "entre" (tanto espacial, quanto temporal) e o substantivo "espaçoentre" ou "meio". Esse termo desempenha um papel fundamental na teoria da percepção de Aristóteles (2010), apresentada no seu livro Sobre a Alma. Essa referência é importante não só porque o termo é tratado como conceito filosófico, mas principalmente por aparecer em uma discussão estética (no sentido de aisthesis, de compreensão pelos sentidos) que, como veremos adiante, configura-se como a principal dimensão epistemológica do conceito de meio. Em sua teoria (ARISTÓTELES, 2010, p. 80 et seq.), cada um dos sentido humanos teria seu respectivo medium: o tocar está designado à pele do corpo, a cor à luz, os sons e os cheiros ao ar ou à água. Para Aristóteles, a percepção sensível (ver, ouvir, tocar, cheirar, sentir o gosto) é uma unidade das funções ontológicas complexas da alma. E, na óptica grega, o olho não existe como um instrumento óptico de formação de imagem mas, para Aristóteles, há alguma coisa "no meio" (metaxú), mesmo que transparente e inominada, que não é o órgão de percepção nem o objeto observado ${ }^{4}$ e que foi traduzida por medium diáfano ${ }^{5}$ por Tomás de Aquino na Idade Média, considerado como o responsável por difundir a palavra medium como um conceito filosófico ${ }^{6}$.

A partir da escolástica, o termo ganhou em abstração, concebido como uma distância necessária e indefinida entre elementos em relação, e aos poucos migrou da percepção estesiológica para a percepção técnica, como algo que preenche esse espaço indefinido ou nele age, sendo empregado pela mecânica, pela acústica e pela óptica do início da modernidade. Apenas no século XVIII, com o mesmerismo e outras correntes místicas e espiritistas é que o termo sairia da física para desaguar no campo religioso ${ }^{7}$.

Nesse ponto, é interessante perceber a introdução da palavra médium (e seu plural, médiuns) no português. Enquanto em línguas modernas, como o alemão e o inglês, o emprego do termo latino medium permaneceu tanto para a descrição de pessoas que afirmam receber mensagens de pessoas mortas ou entidades míticas quanto para a descrição pelas ciências naturais de fenômenos físicos, a língua portuguesa não manteve a tradução corrente, como "meio", mas apresentou um aportuguesamento do termo latino original. Com a proliferação das tecnologias de transmissão, informação e entretenimento

4 Para uma análise do termo $\mu \varepsilon \tau \alpha \xi u ́$ na obra aristotélica e seu desenvolvimento em uma filosofia dos media e uma teoria da percepção, cf. ALLOA, 2001, 2012.

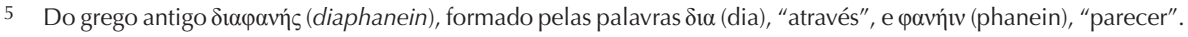
A palavra medieval latina transparente guarda este mesmo sentido.

6 Para uma discussão sobre a tradução de Tomás de Aquino da obra de Aristóteles e a constituição do conceito de medium a partir do termo $\mu \varepsilon \tau \alpha \xi u ́$, cf. HAGEN, 2008; MERSCH, 2010.

7 Para a história do conceito de medium e todas as suas transformações durante a modernidade até o século XX, cf. HOFFMANN, 2002. 
durante o século XX e a crescente influência dos Estados Unidos na formação cultural e política da sociedade brasileira no pós-Guerra, houve um novo aportuguesamento, desta vez do uso em inglês do termo latino medium e seu plural media, provocando o surgimento da palavra mídia (e seu plural, mídias). Se a predominância desse termo pode ser justificada pela sua praticidade em designar dispositivos técnicos de expressão e informação ou conglomerados industriais de entretenimento e produção de notícias, por outro lado, a perda de referência a uma tradição conceitual é bastante problemática, principalmente para a reflexão teórica. Por esse motivo, nossa crítica busca atuar exatamente nos estudos comunicacionais brasileiros, já que, por serem instituídos em uma época em que as tecnologias e empresas ditas "de comunicação" se tornaram um problema prático, teórico e mercadológico, no mais das vezes perdeu-se de vista a relação do conceito de mídia com essa longa tradição que, de forma bastante genérica, foi resumida nesta pequena introdução. Um exemplo do empobrecimento teórico provocado por essa perda associativa é a falta de estudos em comunicação sobre o próprio conceito de médium, como utilizado por religiões praticadas no Brasil. Por isso, antes de encerrarmos essa primeira parte, gostaríamos de fazer uma breve apologia ao termo médium.

Em seu sentido mais corriqueiro, médium significa aquela pessoa que em determinados rituais religiosos serve como intermediária, como mediadora entre os espíritos ou o espaço transcendente e os viventes ou o mundo imanente. Por desempenhar essa função, o médium performa aquele "por meio de" a que referimos anteriormente. Mas nem todo sentido de médium é igual. Há uma diferença fundamental, por exemplo, entre o médium do espiritismo e o médium de algumas religiões brasileiras de matrizes africanas: o primeiro concebe o médium como um instrumento, enquanto o segundo grupo, como um cavalo ${ }^{8}$. Do ponto de vista teórico, essa diferença é essencial e extremamente útil para figurar duas concepções opostas de meio e que se encontram difundidas nas diferentes abordagens dos estudos comunicacionais.

Guardando ainda a concepção de medium advinda do mesmerismo postulado por Franz Anton Mesmer (termo emprestado das ciências naturais), o médium da doutrina espírita formulada por Hippolyte Léon Denizard Rivail (Allan Kardec) pode ser entendido como um instrumento técnico. Influenciado pelo racionalismo e na tentativa de aproximar religião e ciência, o médium espírita se empenha em elaborar uma técnica ou um instrumento de transmissão de mensagens entre os vivos e os mortos. Como técnica e instrumento, esse conceito de médium supõe um sujeito (também em sentido gramatical) ativo, ele se aperfeiçoa para melhor executar essa transmissão. Como será discutido no segundo tópico desse texto, essa visão instrumental do meio é dominante nos estudos comunicacionais.

8 Para um estudo sobre as especifidades teórico-mediais do conceito de médium (como instrumento e cavalo) e sua relação com a Umbanda, cf. JANOWSKI, 2011. 
Por outro lado, existe um conceito fundamentalmente distinto de médium, partilhado por religiões brasileiras de matrizes africanas e também por outras cujo fenômeno ritualístico da possessão assume um papel central. Em algumas correntes do candomblé, da jurema e da umbanda ${ }^{9}$, por exemplo, o médium é chamado de cavalo. Já a partir dessa metáfora, temos a inversão do controle instrumental (da sujeição de forças ao domínio técnico) para um ser assujeitado a forças que não podem ser controladas ${ }^{10}$.

Mas a diferença que queremos ressaltar a partir desses dois ideais de transe refere-se à sua medialidade. Como cavalo, o médium exibe um paradoxo ou aporia medial que será abordado no terceiro tópico desse ensaio, mas que por ora poderíamos resumir da seguinte forma: o médium deve se recolher ou passar despercebido no momento mediúnico para consiga presentificar uma outra entidade - ele está ali, interfere na aparição, mas deve sacrificar sua própria presença ou aspectos fenomênicos no momento em que deixa algo "transparecer". Ele já é um outro, suas características interferem e tomam parte no próprio processo de medialidade (ou mediúnico), mas, se for tematizado (como pai ou mãe de santo) em detrimento da entidade presentificada, ele já não poderá mediar mais nada.

Entre a atividade e a passividade, o entendimento dessas duas concepções nos permite, de uma outra forma, pensar o meio-termo do termo meio. Assim como na sua definição gramatical, o médium atua nesse espaço entre os dois modos. Se pudéssemos definir uma característica geral dos meios, essa seria uma delas. Uma segunda característica pode ser expressa em sua aporia: um meio não consegue mediar a si próprio. Para que um fenômeno surja, ele precisa de uma outra coisa. Logo, apenas um outro meio seria capaz de mediar um outro meio. Como veremos mais adiante, a reflexividade do medial pressupõe, portanto, um amedial - algo que não seja meio, para que ele mesmo seja possível. Uma terceira característica que será abordada neste texto é a duplicidade intrínseca a qualquer meio: ao mesmo tempo em que se constitui como a própria condição de possibilidade da relação, da aparição, da transmissão etc., ele as restringe. Para além de teorias integradas ou apocalípticas sobre os usos de um meio de expressão e informação, identificar sempre esses elementos de possibilidades e restrições inscritas em todo meio é tarefa de uma "teoria dos meios".

O imperativo de se responder primeiramente à questão "o que é um meio?" delimita não só o objeto estudado, como a própria abordagem epistemológica. Com o intuito de compor um contraste à proposição de meio como médium, no próximo tópico abordaremos três sentidos comumente utilizados no campo das ciências da comunicação no país: o meio como canal, como prótese e como signo.

9 Devido ao escopo e tamanho deste trabalho, assumimos que essa classificação binária é extremamente simplista e sua principal intenção é a de mostrar a importância do conceito de médium para os estudos comunicacionais brasileiros. A abordagem do conceito de médium em religiões de tradição oral e com uma pluralidade variações internas ainda demanda um estudo mais detalhado. Para uma introdução sobre religiões brasileiras de matrizes africanas, cf. LIMA, 1979; MAGNANI, 1991; PRANDI, 1990, 2007; SILVA, 2000.

10 Para uma ilustração desta diferença, cf. PRANDI, 1990, p. 64. 


\section{Canais, próteses e signos ${ }^{11}$}

A palavra canal é derivada do latim, canna, que literalmente significa um cano pequeno, uma canaleta, um lugar para escoar água ${ }^{12}$. O meio como canal, portanto, é entendido como um instrumento de armazenamento e transporte. Um canal é sempre um lugar físico através do qual algo que foi previamente codificado para ser transmitido deve fluir ao seu destino, assim como água canalizada.

Canal é comumente uma das primeiras definições de meio apresentada nos cursos de teoria da comunicação, quando se discute o modelo matemático de comunicação. Seu conhecido esquema divide o processo de transmissão de informação em cinco componentes essenciais e irredutíveis: fonte de informação; transmissor/codificador; canal; receptor/decodificador; e destino. Mesmo que consecutivos autores e teorias tenham ampliado ou revisado este modelo, essa estrutura básica permaneceu praticamente inalterada em sua forma e função. Consequentemente, nunca houve um modelo que fosse maleável o suficiente para cobrir áreas tão distintas do saber científico, não apenas a matemática ou as engenharias, mas também, com a cibernética como sua principal promotora, a antropologia, a psicanálise, a biologia e a neurologia.

Uma das pedras fundamentais para a teoria matemática da comunicação foi a publicação de um artigo de mesmo nome escrito pelo matemático e engenheiro eletricista norte-americano Claude Shannon. O artigo de Shannon é fruto das suas pesquisas sobre a transmissão de informações telegráfica. Sua meta era buscar meios de melhorar a transmissão (ou em suas próprias palavras, a comunicação) de informações com a menor margem de perda ou ruído possível de um lugar para outro. Naturalmente, o que importa para a teoria de Shannon não era o sentido da transmissão, a semântica de uma mensagem, mas o potencial de um sistema operar qualquer tipo de escolha obtida dentro de um espaço de possibilidades. $\mathrm{E}$, consequentemente, o meio foi definido ou equiparado a um canal para a transmissão dessa informação (SHANNON; WEAVER, 1949, p. 34).

É importante ressaltar aqui que, quando o meio é concebido como um canal, a própria medialidade deixa de ser considerada, mesmo que ele seja o local onde o ruído - o grande mal a ser combatido pelas teorias matemáticas da informação - pode ocorrer. O mais importante é a mensagem, por isso a redundância é um elemento crucial para suplantar a imprevisibilidade do canal. Curiosamente, aumentar a redundância é reduzir a própria informação, já que ela está ligada intrinsecamente à possibilidade, i.e., ao número de escolhas. Visto de outra forma, quanto maior o ruído, maior a informação, maior a incerteza a ser combatida. Assim, a redundância na teoria matemática da comunicação é fundada na ideia de equivocação, ou seja, naquilo que mede a proporção de incerteza em uma determinada mensagem quando o sinal, por sua vez, já é conhecido.

11 A discussão de alguns conceitos e concepções apresentada neste texto também pode ser lida como uma reconsideração de temas inicialmente discutidos em minha tese de doutorado (LIESEN, 2014a).

12 Para um resumo de teorias dos meios como canais, cf. ROESLER; STIEGLER, 2005, p. 125-126. 
No contexto das tradicionais teorias da comunicação, o meio só viria a ser de fato abordado com o teórico canadense Marshall McLuhan (1964) e seu conhecido mantra "o meio é a mensagem", título do primeiro capítulo da sua principal obra, traduzida como Os Meios de Comunicação como Extensão do Homem. A palavra empregada por McLuhan no original é medium e sua generalização conceitual - o meio é qualquer extensão técnica dos sentidos humanos - pode ser situada dentro de uma tradição da filosofia da técnica que pode ser resumida como protética.

Tal posição pode ser encontrada, por exemplo, já no final do século XIX, na filosofia da técnica de Ernst Kapp (2015), que concebe a história do ser humano como a história da invenção de ferramentas mais eficazes. Em sua obra, já encontramos analogias do sistema nervoso ao sistema telegráfico (o que mais tarde se tornaria o lugar comum de analogias com rede de computadores), dos aparatos ópticos ao sistema de visão. Ou seja, o homem refletiria em suas produções as funções e relações naturais do seu corpo. Assim como em McLuhan, a técnica remete a uma medida antropológica.

Mesmo sem reportar à obra de Kapp, McLuhan, em sua conhecida alusão ao mito de Narciso, defende que o homem não reconhece o meio como extensão de si, assim como o Narciso narcotizado não se reconhecia em seu próprio reflexo. Os meios, por atuarem diretamente em nossos sentidos, alteram nossa própria percepção e consciência. Um elemento fundamental na teoria do teórico canadense, e muitas vezes ignorado pelos teóricos da comunicação, é que, além de extensões, os meios também são autoamputações. Ou seja, McLuhan já aponta para o princípio medial da duplicidade entre possibilidade e restrição. Entretanto, a generalidade do seu conceito de meio e seu caráter instrumental torna inócua a tentativa de, por meio de sua teoria, discorrer sobre qualquer especifidade da operatividade e da função medial. Outro problema da teoria protética é seu generativismo: os meios são geradores de sentidos, ao contrário das teorias dos canais para os quais os meios são apenas transmissores. Como veremos no próximo tópico, mesmo possuindo um caráter transformador (e não neutro, como para teorias instrumentais), um meio não pode produzir aquilo que ele media - é necessário sempre uma outra coisa que o afete.

Por fim, uma outra maneira de deslocamento do problema da medialidade dentro dos estudos de comunicação foi a definição ou equiparação de meio ao conceito de signo. É através do signo que a semiótica também fornece uma base material ao sentido. O signo é aquilo que põe em relação alguma coisa a sua significação. Assim como o meio, ele partilha de uma função essencialmente relacional. A referência entre os dois conceitos pela semiótica havia sido realizada pela sua principal fonte, na obra do filósofo norte-americano Charles Sanders Peirce.

A partir de 1906, a concepção de signo como medium se tornou mais frequente nos escritos peircianos ${ }^{13}$. No $\S 9$ do seu ensaio "A base do pragmatismo nas ciências normativas", escrito neste mesmo ano, Peirce (1998, p. 391) afirma que um signo

13 Cf. a nota 22 escrita pelos editores de sua obra em PEIRCE, 1998, p. 544. 
"se adéqua perfeitamente à função de um meio [medium] de comunicação". O filósofo identifica no signo a mesma relação triádica pertencente ao meio, que age de forma passiva em relação ao objeto e de forma ativa em relação ao interpretante do signo.

Entretanto, dois problemas surgem a partir dessa identificação conceitual entre signo e meio. De um lado está o problema do apriorismo medial. Para Peirce, não existe relação comunicacional para além da semiose (PEIRCE, 1965, p. 165 [CP 5.251]). Ou seja, sua teoria fundamenta uma linha de pensamento que não admite que haja um fora do meio, já que todo conhecimento ou reconhecimento seriam mediados (por meio de signos). A partir dessa concepção um topos comum foi instaurado nas humanidades que ecoa aquela concepção de que o real é um efeito dos meios, de que os meios constroem o real, produzem o saber, representam as ideias, guardam as lembranças, possibilitam o agir comum e a comunicação, ou seja, uma postura teórica que assume certo axioma de que os media são as próprias condições de possibilidade de qualquer experiência. Na leitura crítica do filósofo alemão Dieter Mersch (2004, p. 75): “O que se pode compreender é mediatizado. O ser do ente se revela necessariamente como um ser mediatizado" ${ }^{14}$. Com isso, tal visão que entende a nossa relação com o mundo como exclusivamente mediada - pratica em uma forma de idealismo medial, em uma totalização paralisante face ao problema do conhecimento do meio em si, já que tudo o que é dado e percebido seria seu produto: como é que a medialidade poderia ser descrita, situada, apreendida? Como experienciar o medial dentro do próprio meio?

Um outro problema da indiferenciação entre meio e signo é a consequente indiferenciação entre materialidade e estruturalidade. A materialidade é uma espécie de conceito-limite para a semiótica na medida em que um material até participa da relação, mas não parece ser relevante para ela. Essa diferença entre materialidade do meio e estruturalidade do signo foi explorada pela filósofa alemã Sybille Krämer (2008, p.35 et seq.) para definir uma linha entre estudos mediais e estudos semióticos. O signo é, em geral, definido como algo que está-para alguma outra coisa. Ele aponta para algo que está situado além de sua própria materialidade. O meio, por sua vez, põe em atividade uma operação contrária: a própria mensagem que surge no acontecimento medial é aqui que se percebe. O meio torna-se secundário: ele é neutralizado, ele se recolhe durante sua operatividade. Ao contrário de uma relação concebida como sígnica, em que para além do sensual está o sentido, a perspectiva de uma teoria dos meios supõe que para além da mensagem visível encontra-se o meio invisível.

\section{O meio de percepção do meio}

Mas então como abordar um objeto que se recolhe durante a sua ação? Haveria uma possibilidade de reflexão medial dentro do próprio meio? Se nem tudo é um meio,

14 Tal transcendentalidade e ubiquidade do meio também foi consistentemente abordada e criticada na obra da filósofa Sybille Krämer (1998, 2003). 
se existe algo que poderíamos chamar de amedial que o possibilitaria, como poderíamos exibir esse outro do médium?

Essas são algumas perguntas que movem duas das mais profícuas teorias dos meios do ponto de vista epistemológico: a dia-fenomenologia, do filósofo Emmanuel Alloa (2001, 2012a, 2012b, 2013a, 2013b) e a teoria negativa dos meios, do filósofo Dieter Mersch (2002a, 2002b, 2013, 2003a, 2003b, 2004, 2007a, 2007b, 2008, 2010b, 2011).

Em comum, esses dois autores estão situados dentro da tradição estética do conceito de medium que, como vimos no início deste texto, tem a teoria da percepção aristotélica como precursora. Mas, antes de observamos algumas particularidades das duas propostas, é bom lembrar que a abordagem que situa os estudos dos meios no campo das teorias da percepção e da estética foi reelaborada em vários momentos durante o século XX, por exemplo, com a filosofia e teoria da linguagem do pensador alemão Walter Benjamin (2010 ${ }^{15}$ e na teoria da percepção de Fritz Heider (2005), cuja distinção entre forma e meio (a forma só é possível a partir de um meio, como na relação figura-fundo) serve de base para afirmar que os objetos do reconhecimento agem sobre os órgãos de sentido através de mediações e essas mediações ocorrem através de meios (p.ex. luz, ar etc.). Tal conceito sistêmico de meio influenciaria mais tarde a obra de Niklas Luhmann.

Mas, diferentemente de Heider, Alloa desloca o conceito de meio para o centro da fenomenologia. Apreendido como aquilo que dá o que aparece, compreender a função do meio é fundamental para o estudo da experiência. Essa função pode ser expressa na preposição através (em grego, dia), cuja base teórica pode ser encontrada em seu estudo sobre a teoria da percepção de Aristóteles e o conceito de metaxú (ALLOA, 2001). E seria a própria condição sine qua non da faculdade perceptiva. Seguindo a tradição fenomenológica, Alloa considera o corpo como o primeiro meio que é afetado pelo mundo - o toque é primeira coisa que nos afeta. Sua dia-fenomenologia é uma tentativa de deslocamento do sujeito da experiência, que, devido ao caráter passivo da medialidade, é ator, mas nunca autor da experiência, já que em toda percepção é o meio que nos atravessa. Por isso, toda fenomenalidade só pode ser entendida como trans-fenomenalidade, já que nenhum fenômeno seria capaz de se presentificar sozinho.

Mas, se toda percepção é mediada, mais uma vez nos deparamos com a aporia medial de que falávamos acima, ou seja, com o paradoxo de que um meio só pode ser percebido através de uma nova mediação. Além disso, a perfeição de um meio está na sua capacidade de ser esquecido durante sua operação, isto é, enquanto meio nenhum meio consegue co-mediar sua materialidade. Nós observamos através dos meios, mas eles não podem observar a si próprios. Para darmos um exemplo, durante a leitura de um livro, elementos como a impressão das letras, formatação, cor das páginas, peso etc. devem ser esquecidos para que a leitura de fato ocorra. Caso esses elementos fossem tematizados,

15 Nós já havíamos abordado o conceito de medium em Walter Benjamin e o problema da sua recepção nos estudos comunicacionais brasileiros em outra ocasião. Cf. LIESEN (2014b). 
não haveria meio algum que pudesse ser associado ao médium que possibilitava a leitura. Por isso, o meio nunca pode ser conhecido em sua inteireza.

Para usarmos uma fórmula de Mersch (2002a, p. 85): "No meio o meio permanece, como meio, desconhecido". E aí reside a radicalidade da sua teoria negativa dos media que, contrariamente a Alloa, afirma ainda que nem tudo se dá por um meio (por exemplo, qual seria o meio do silêncio ou da dor?). A negatividade é um instrumento metodológico para a possibilidade de uma reflexividade medial, já que o meio só pode ser percebido indiretamente, através de epistemologias singulares que deem conta de um evento de mediação que é sempre singular. Por esse motivo, a arte se coloca como uma grande técnica de exposição da medialidade de um meio, pois ela atua exatamente em sua fronteira, ou seja, no amedial que sempre acomete o meio.

Para Mersch, esse amedial é a materialidade que condiciona a própria medialidade do médium ${ }^{16}$. As materialidades delimitam o potencial de qualquer meio e não podem se manifestar como estruturas, ou seja, a produtividade de um médium é sempre limitada em uma limitação que o transcende. A materialidade resiste à sua própria medialidade. Essa ideia é muito próxima do conceito aristotélico de techné, já que um meio não pode investir no seu próprio material, alterando sua natureza, mas na sua forma.

Tal relevância da reelaboração conceitual da materialidade para as teorias dos meios opera como uma crítica a correntes que defendem a possibilidade de meios imateriais, principalmente a partir do triunfo da sintaxe computacional. Já Friedrich Kittler (1993, p. 235), um dos mais importantes teórico dos meios (concebidos dentro da tradição técnica e instrumental), havia afirmado que não existem softwares, pois, no fim, são impulsos elétricos atuando no hardware, e que o limite real da simulação é o tempo e toda máquina digital consome tempo para o cálculo dos seus algoritmos.

Esse direcionamento epistemológico da busca pela materialidade dos meios pode ser entendido como uma reação, nas ciências humanas, não só à perda da referência à concretude das coisas, mas também como uma tentativa de abordar pressupostos ainda não significantes, tanto do local, quanto dos suportes e das modalidades da gênese do sentido. É nesse campo de estudos que a teoria dos meios, como esboçada até aqui, ganha importância como especificidade epistêmica, capaz de lançar questões em nome próprio.

\section{Algumas considerações finais}

Como foi discutido no decorrer deste ensaio, o sentido ou função mais geral e abstrata do medial como mediação é sua relacionalidade. Entretanto, ela é diferente da função representacional, referencial, denotativa ou simbólica do conceito de signo ou de qualquer outro conceito de relacionalidade que atue sob a marca da partícula "como" -

16 Em um trabalho posterior, já havíamos abordado o conceito de materialidades para os estudos de meios e de comunicação, cf. LIESEN (2015). 
algo é apresentado "como" alguma coisa, está no "lugar de" uma outra coisa etc. Como vimos, a função do meio como médium, a operação de sua medialidade, é expressa pela locução por meio de ou através de.

Desta forma, a referencialidade do meio não é estruturada como um sistema de posições que remetem a uma atribuição cujo padrão ou diagrama possa ser analisado, mas apresenta-se, antes de tudo, como uma (co)produção, como um processo de cocriação ou poiesis. Como esclarece Dieter Mersch (2015, p. p.14), em esquemas semióticos ou semiológicos, o conceito de mídia parece ocupar uma posição ou localidade diferente e, portanto, assume um status diferente, o que torna seu esclarecimento precário desde o início. Se a mediação ou medialidade é usada como um ponto de partida preliminar, elas parecem apontar para um "meio" que inicialmente permanece tão inexplicável quanto incontornável. E isso pode ser entendido de duas maneiras: por um lado, um "meio" é sempre uma entidade material que possui uma substância que tanto possibilita quanto limita; e, por outro lado, é um centro constantemente evanescente ou em decomposição, um "intermediário" baseado em uma diferença fundamental que, embora não exista sem uma base material, divide o espaço da mediação desde o início e desaparece no processo de mediação, tornando-se decifrável apenas como um traço, como um distanciamento (espacial) ou deferência (temporal).

Há uma pedra no meio do caminho dos estudos comunicacionais brasileiros - e ela se chama "estudos dos meios". Poder-se argumentar que esses dois campos possuem objetos diferentes dos das teorias da comunicação já sedimentadas. Entretanto, acreditamos que esses estudos deveriam receber um melhor acolhimento pelos cursos de comunicação social no país, não apenas pelo entendimento de que toda comunicação - não importa qual definição lhe seja atribuída - precisa de um meio para que ocorra, mas principalmente pela recorrente confusão epistemológica e metodológica que não diferencia os estudos de comunicação e dos meios.

Maurício Liesen é professor colaborador do PPGCOMUFPR como bolsista PNPD/CAPES. É doutor em pela USP (2014) e mestre pela UFRJ (2010). Entre 2014 e 2017, atuou como pesquisador e professor visitante no curso de graduação e mestrado em Ciências Europeias dos Media da Universidade de Potsdam, Alemanha. Em 2017, concluiu estágio pós-doutoral na USP sob os auspícios da FAPESP.

mauricioliesen@ufpr.br 


\section{Referências}

ALLAN, R. J. The Middle Voice in Ancient Greek. A Study of Polysemy. Leiden e Boston: Brill, 2003.

ALLOA, E. Das durchscheinende Bild: Konturen einer medialen Phänomenologie. Zurique: Lars Müller, 2001.

Metaxy oder Warum es keine immateriellen Medien gibt. In: $\mathrm{KOCH}$, Gertrud; MAAR, Kirsten \& MCGOVERN, Fiona (Org.). Imaginäre Medialität - Immaterielle Medien. Munique: Fink, 2012a., p. 13-34.

. Das Medium scheint durch. Talbot - Stella - Hantaï. In: FINKE, Marcel \& HALAWA, Mark A. (Org.). Materialität und Bildlichkeit. Visuelle Artefakte zwischen Aisthesis und Semiosis. Berlim: Kadmos, 2012b, p. 68-85.

Erscheinung und Ereignis: zur Zeitlichkeit des Bildes. Munique: Fink, 2013a.

rscheinungsereignisse. Zur Einleitung. In: ALLOA, Emmanuel (Org.). Erscheinung und Ereignis. Zur Zeitlichkeit des Bildes. München: Wilhelm Fink, 2013b.

ALLOA, E. et al. Materialität und Bildlichkeit. Visuelle Artefakte zwischen Aisthesis und Semiosis. Berlin: Kulturverlag Kadmos, 2012.

ARISTÓTELES. Sobre a alma. Tradução Ana Maria Lóio. Lisboa: Imprensa Nacional-Casa da moeda, 2010.

BENJAMIN, W. Sprache und Geschichte: Philosophische Essays. Stuttgart: Reclam, 2010.

BLUTEAU, R. Vocabulário Portuguez e Latino: L-N [Vol. 5]. Coimbra: Collegio das Artes da Companhia de Jesus, 1716.

HAGEN, W. Metaxy: Eine historiosemantische Fußnote zum Medienbegriff. In: MÜNKER, Stefan \& ROESLER, Alexander (Org.). Was ist ein Medium? Frankfurt am Main: Suhrkamp, 2008, p. 13-29.

HEIDER, F. Ding und Medium. Berlim: Kulturverlag Kadmos, 2005.

HOFFMANN, S. Geschichte des Medienbegriffs. Hamburgo: Felix Meiner, 2002.

JANOWSKI, N. "Apparate" für die Geister, "Pferde" für die Götter. Spirituelle Medien in der Umbanda. In: FISCHER-LICHTE, Erika et al. (Org.). Wahrnehmung und Medialität. Tübingen, Basel: Francke, 2011, p. 301-320.

KAPP, E. Grundlinien einer Philosophie der Technik. Zur Entstehungsgeschichte der Kultur aus neuen Gesichtspunkten. Hamburgo: Felix Meiner, 2015.

KITTLER, F. Draculas Vermächtnis. Technische Schriften. Leipzig: Reclam, 1993.

KRÄMER, S. Das Medium als Spur und als Apparat. In: KRÄMER, Sybille (Org.). Medien Computer Realität: Wirklichkeitsvorstellungen und Neue Medien. Frankfurt am Main: Suhrkamp Verlag, 1998, p. 73-94.

Erfüllen Medien eine Konstitutionsleistung? Thesen über die Rolle medientheoretischer Erwägung beim Philosophieren. In: MÜNKER, Stefan; ROESLER, Alexander; SANDBOTHE, Mike (Org.). Medienphilosophie. Beiträge zur Klärung eines Begriffs. Frankfurt am Main: Fischer Taschenbuch Verlag, 2003, p. 78-90.

LIESEN, M. Excommunicatio: ensaio para uma teoria negativa da comunicação. 2014. 191 p. Tese (Doutorado) - Escola de Comunicações e Artes, Universidade de São Paulo, São Paulo, 2014a. Disponível em: https://teses.usp.br/teses/disponiveis/27/27152/tde-2005201 
. O medium silenciado: re-flexões teórico-comunicacionais sobre uma teoria dos media em Walter Benjamin. Revista Matrizes, São Paulo, v. 8, n. 2, p. 243-257, 2014 b.

Materialidades mediais. Notas sobre uma perspectiva pós-hermenêutica. Revista Contracampo, Niterói, v. 33, n. 2, p. 4-20, 2015.

LIMA, F. F. Malungo: Decodificação da Umbanda. Contribuição à História das Religiões. Rio de Janeiro: Civilização Brasileira, 1979.

MAGNANI, J. G. C. Umbanda. 2. ed. São Paulo: Ática, 1991.

MCLUHAN, M. Understanding Media: The Extensions of Man. New York: New American Library, 1964.

MERSCH, D. Ereignis und Aura: Untersuchungen zu einer Ästhetik des Performativen. Frankfurt am Main: Suhrkamp Verlag, 2002a.

Was sich zeigt. Materialität, Präsenz, Ereignis. München: Fink, 2002b.

. Wort, Bild, Ton, Zahl: Modalitäten medialen Darstellens. In: MERSCH, Dieter (Org.). Die Medien der Künste: Beiträge zur Theorie des Darstellens. München: Wilhelm Fink Verlag, 2003a, p. $9-49$.

. (Org.). Die Medien der Künste: Beiträge zur Theorie des Darstellens. Munique: Wilhelm Fink, 2003b.

. Medialität und Undarstellbarkeit. Einleitung in eine "negative" Medientheorie. In: KRÄMER, Sybille (Org.). Performativitat und Medialität. Munique e Paderborn: Wilhelm Fink, 2004, p. 75-96.

Die Frage der Alterität: Chiasmus, DIfferenz und die Wendung des Bezugs. In: DALFART, Ingolf U. \& STOELLGER, Philipp (Org.). Hermeneutik der Religionen. Tübingen: Mohr Siebeck, 2007a, p. 35-57.

Orte der Bedeutung: sechs Thesen zu Sprache und Alterität. In: BUBNER, Rüdiger \& HINRICHS, Gunnar (Org.). Von der Logik zur Sprache: Stuttgarter Hegel-Kongreß 2005. Hamburg: Klett-Cotta, 2007b, p. 349-364.

Tertium datur: Einleitung in eine negative Medientheorie. In: MÜNKER, Stefan \& ROESLER, Alexander (Org.). Was ist ein Medium? Frankfurt am Main: Suhrkamp Verlag, 2008.

. Meta/Dia Zwei unterschiedliche Zugange zum Medialen. Zeitschrift für Medien-und Kulturforschung, v. 2010, n. 2, p. 185-208, 2010a.

. Posthermeneutik. Hamburgo: Akademie Verlag, $2010 \mathrm{~b}$.

Einführung in die Medienkulturwissenschaft. Vorlesungen. Potsdam: EMW Uni Potsdam, 2011.

. Ordo ab chao - Order from Noise. Berlim: diaphanes, 2013.

Wozu Medienphilosophie. Eine programmatische Einleitung. In: MERSCH, Dieter; MAYER, Michael (Org.). Internationales Jahrbuch für Medienphilosophie - Einschnitte: Zur Genesis und Geltung medienphilosophischer Reflexionen. Berlin/München/Boston: Walter de Gruyter, 2015. p. $13-48$.

PEIRCE, Charles Sanders. Colected Papers: Volume V (Pragmatism and Pragmaticism). Cambridge: Belknap Press of Harvard University Press, 1965.

The Essential Peirce: Selected Philosophical Writings. Volume 2 (1893-1913). Bloomington e Indianapolis: Indiana University Press, 1998.

PRANDI, Reginaldo. Modernidade com feitiçaria: candomblé e umbanda no Brasil do século XX.

Revista Tempo Social, vol.2, no.1, São Paulo, Jan./Jun 1990. 
. As religiões afro-brasileiras nas ciências sociais: uma conferência, uma bibliografia. Revista Brasileira de Informação Bibliográfica em Ciências Sociais, v. 63, n. 1, p. 1-30, 2007.

ROESLER, A,; STIEGLER, B. (Org.). Grundbegriffe der Medientheorie. Paderborn: Wilhelm Fink, 2005.

RÖTTGERS, K.; SCHMITZ-EMANS, M. (Org.). Mitte. Philosophische, medientheoretische und ästhetische Konzepte. Essen: Die Blaue Eule, 2006.

RÖTTGES, H. M. In: RITTER, Joachim \& GRÜNDER, Karlfried (Org.). Historisches Wörterbuch der Philosophie [L - Mn]. Basileia/Stuttgart: Schwabe \& Co., 1980, p. 1421-1424.

SCHMITZ-EMANS, M. Zur Semantik der "Mitte". Vorüberlegungen. In: RÖTTGERS, Kurt \& SCHMITZEMANS, Monika (Org.). Mitte. Philosophische, medientheoretische und ästhetische Konzepte. Essen: Die Blaue Eule, 2006. p. 7-15.

SCHRÖTER, J. (Org.). Handbuch Medienwissenschaft. Stuttgart e Weimar: J. B. Metzler, 2014.

SHANNON, C. E.; WEAVER, W. The Mathematical Theory of Communication. Urbana: University of Illinois Press, 1949.

SILVA, V. G. da. Candomblé e Umbanda: Caminhos da devoção brasileira. São Paulo: Ática, 2000. 